\title{
Exploring parental behavior and child interactive engagement: a study on children with a significant cognitive and motor developmental delay
}

Ines Van keer ${ }^{\mathrm{a},{ }^{*}}$, Stephy Colla ${ }^{\mathrm{a}}$, Karla Van Leeuwen ${ }^{\mathrm{a}}$, Carla Vlaskampp ${ }^{\mathrm{b}}$ Eva Ceulemans ${ }^{\mathrm{a}}$, Karel Hoppenbrouwers ${ }^{\mathrm{c}}$, Annemie Desoete ${ }^{\mathrm{d}}$, Bea Maes ${ }^{\mathrm{a}}$

${ }^{a}$ Catholic University of Leuven, Faculty of Psychology and Educational Sciences, Leopold Vanderkelenstraat 32, bus 3765, 3000 Leuven, Belgium.

${ }^{\mathrm{b}}$ University of Groningen, Department of Special Needs Education and Youth Care, Grote Kruisstraat 2/1, 9712 TS Groningen, The Netherlands

${ }^{\mathrm{c}}$ Catholic University of Leuven, Faculty of Medicine, Kapucijnenvoer 35 blok d, bus 7001, 3000 Leuven, Belgium

${ }^{\mathrm{d}}$ University of Ghent, Faculty of Experimental Clinical and Health Psychology, Henri Dunantlaan 2, 9000 Gent, Belgium

* Corresponding author at: Vanderkelenstraat 32, bus 3765, 3000 Leuven, Belgium. Tel: +32 16 376892, E-mailaddress: ines.vankeer@kuleuven.be 


\title{
Exploring parental behavior and child interactive engagement:
}

\author{
a study on children with a significant cognitive and motor \\ developmental delay
}

\begin{abstract}
Background \& Aims: Parenting factors are one of the most striking gaps in the current scientific literature on the development of young children with significant cognitive and motor disabilities. We aim to explore the characteristics of, and the association between, parental behavior and children's interactive engagement within this target group.

Methods \& Procedures: Twenty-five parent-child dyads (with children aged 6-59 months) were video-taped during a 15-minute unstructured play situation. Parents were also asked to complete the Parental Behavior Scale for toddlers. The video-taped observations were scored using the Child and Maternal Behavior Rating Scales.

Outcomes \& Results: Low levels of parental discipline and child initiation were found. Parental responsivity was positively related to child attention and initiation.

Conclusions and implications: Compared to children with no or other levels of disabilities, this target group exhibits large differences in frequency levels and, to a lesser extent, the concrete operationalization of parenting domains. Further, this study confirms the importance of sensitive responsivity as the primary variable in parenting research.
\end{abstract}

Keywords: parental behavior; child interactive engagement; severe and multiple disabilities; profound and multiple disabilities 


\section{Introduction}

A child's development is the product of continuous dynamic interactions between the child and the experiences provided by his or her social settings (Lerner, Rothbaum, Boulos, \& Castellino, 2002; Sameroff, 2009). Although interrelated with nonfamilial influences and the broader context in which families live (Collins, Maccoby, Steinberg, Hetherington, \& Bornstein, 2000), the most proximal and most influential social setting is the child's family (Bronfenbrenner, 1986; Lochman, 2004).

The idea that especially parents are primary agents of developmental change in their children is reflected in an extensive body of research on parenting behavior (Mahoney \& Nam, 2011; Sameroff, 2010). In typically developing children, high levels of parental support (e.g., sensitive responsiveness, warmth and stimulation) are generally found to be associated with adaptive child outcomes in a variety of developmental domains (e.g., Farah et al., 2008; Landry, Smith, Swank, Assel, \& Vellet, 2001; Larzelere, Morris, \& Harrist, 2013; Stams, Juffer, \& van Ijzendoorn, 2002; Zhou et al., 2002). On the contrary, (intrusive) directiveness and negativity appear to be inversely associated with developmental outcomes (e.g., Ispa et al., 2004; Larsson, Viding, Rijsdijk, \& Plomin, 2008).

Mahoney and Nam (2011) pointed out that the same general patterns of parenting associated with optimal development in typically developing children are evident in studies on children with a developmental delay. For example, maternal sensitivity and responsiveness are inversely associated with behavioral problems and positively related with appropriate behavior, communication and general development in young children with intellectual disabilities (Warren \& Brady, 2007). Negative parent-child interactions are associated with child behavioral problems (Hastings, Daley, Burns, \& Beck, 2006), while parental scaffolding has 
been demonstrated to be predictive for the social competence in children with developmental delays (Baker, Fenning, Crnic, Baker, \& Blacher, 2007). A recent meta-analysis of 14 studies including 576 participants showed an association between positive parenting styles and more adaptive functioning in children with developmental disabilities (Dyches, Smith, Korth, Roper, \& Mandleco, 2012). Research into the association of (different levels of) directiveness with (positive as well as negative) child outcomes has shown mixed results, although higher levels of parental directiveness are often observed in children with lower levels of cognitive functioning (Guralnick, Neville, Hammond, \& Connor, 2008; Spiker, Boyce, \& Boyce, 2002).

However, within the target group of children with a significant cognitive and motor developmental delay, knowledge on parenting is very scarce (Chadwick, Cuddy, Kusel, \& Taylor, 2005; Van keer \& Maes, 2016). The combination of significant motor and cognitive limitations, resulting in a high dependency of these children on their immediate social setting, provides parents with complex and unique challenges (Fagnart, 2011; Horn \& Kang, 2012; McCollum, 2002). For example, in a study of Wilder, Axxelson and Granlund (2004), parents perceived their children with profound and multiple disabilities to have difficulties initiating interaction and maintaining attention, and perceived themselves to be less competent in understanding the child's communication and in directing and maintaining the child's attention. However, it is unclear whether these challenges result in different patterns of parenting within this specific target group. Research on parenting young children with a significant cognitive and motor disability is especially warranted, since the early years might constitute an unique window of opportunity to influence children's developmental trajectories (Guralnick, 2005; Narvaez, 2012; Nelson, 2000). 
Integrating several conceptually and empirically grounded models of child development, such as the transactional model (Sameroff, 2009), the developmental systems theory (Ford \& Lerner, 1992), the ecological theory (Bronfenbrenner, 2001) and the parenting process model (Belsky, 1984), Guralnick (2011) described a framework for understanding contextual influences on early (typical and atypical) child development. This framework encompasses risk and protective factors at three levels: child's current developmental characteristics, family patterns of interaction and family resources. Overall, the importance of family patterns of interaction is greatly stressed and it is proposed that the central task of early intervention is to establish, restore and/or stimulate family patterns of interaction to the most optimal level as possible in order to optimize the child's developmental opportunities. As to how this process unfolds, Mahoney and colleagues state that parent-child interactions influence child development by stimulating pivotal developmental behaviors (Mahoney, Boyce, Fewell, Spiker, \& Wheeden, 1998; Mahoney \& Nam, 2011). Pivotal behaviors are "behaviors that are central to wide areas of functioning such that a change in the pivotal behavior will produce improvement across a number of behaviors" (Koegel, Koegel, \& Carter, 1999, p. 577). Interactive engagement behaviors, such as attention and initiation, are considered by constructivist theories to be core processes of learning and development and thus regarded as pivotal developmental behaviors (Kim \& Mahoney, 2004). Mahoney, Kim and Lin (2007) presented data indicating that the degree to which parents engage in responsive interaction with their child is associated with the child's use of these pivotal behaviors.

Based on these previous findings, we aim to

1. provide a general characterization of parental behavior towards young children with a significant cognitive and motor developmental delay,

2. provide a general characterization of these children's interactive engagement, 
3. explore the association between parental behavior and children's interactive engagement in this target group.

\section{Method}

\subsection{Participants}

Twenty-five unique parent-child dyads participated in the study. They were recruited through hospitals, diagnostic centers, early intervention teams and specialized day care centers in Flanders (Belgium; $n=11)$ and the Netherlands $(n=14)$. Professionals within these organizations were asked (by mail and/or by telephone) to inform potential participants on the study and to bring them into contact with the researchers. Parents were free to choose whether the mother or father participated in the study. We included children between the age of 6 months and 4 years, who were at least spending their weekends and holidays with their family. We did not include children before the age of 6 months because clear indications of a significant developmental delay should be present and we wanted to respect the high emotional stress of parents in the first months after birth. A significant cognitive delay was operationalized using the 'Tandemlijst' (Stadeus, Windey, Vermier, \& Van Driessche, 1994). We included children functioning below a quarter of their chronological age, which is associated with the description of a profound intellectual disability (Grossman, 1973; Hogg, Foxen, \& McBrien, 1981; Vig \& Sanders, 2007). The Tandemlijst is specifically developed for young children with a developmental delay. It includes the developmental steps and milestones used in early intervention programs. By describing the cognitive developmental domain separately and in detail, the influence of the motor limitations on the estimation of cognitive functioning is minimized as much as possible. A significant motor delay was operationalized using the 'Gross Motor Function Classification System - Expanded \& Revised' (GMFCS-E\&R; Palisano, Rosenbaum, Bartlett, \& Livingston, 2007). The GMFCS is specifically developed for and 
widely used in research on relatively young children with significant motor limitations and shows a good reliability and predictive value (Wood \& Rosenbaum, 2000). Also, the instrument provides descriptions of motor abilities for different age bands, including 0 to 2,2 to 4 and 4 to 6 years. We included children functioning at level IV or V (indicating a severe impairment) and, additionally, level III when the child was less than 2 years old (since combining level III, IV and V has a better predictive value at this young age; Gorter et al., 2009). Detailed inclusion criteria are available from the first author upon request. The presence of a significant developmental delay in both the cognitive and the motor domain was regarded as a necessary and sufficient inclusion criterion (Nakken \& Vlaskamp, 2007). Children who only showed a significant delay in one of the two domains were not included. We formulated no criteria regarding the cause of the developmental delay and the presence of additional constraints (sensory disabilities, health problems, comorbid diagnoses such as ASS, etc.). Detailed background information on the parent-child dyads is presented in Table 1.

[Insert Table 1 here]

\subsection{Procedure and Instruments}

Two types of parental behavior were examined: parent's interactional style (measured through observation) and parenting behavior (measured through self-report). Child's interactive engagement was simultaneously assessed through the observation procedure. This study was approved by the Social and Societal Ethics Committee (KU Leuven) and written informed consent was obtained from parents prior to data collection.

\subsubsection{Child's interactive engagement and parent's interactional style}


Participating parent-child dyads were video-taped during a 15-minute unstructured play situation, at home or at the familiar day care facility of the child. Parents were instructed to engage with the child as they would normally do, but were not informed on the parental and child behaviors of interest to the study. Due to the significant (cognitive, motor and/or sensory) limitations and idiosyncratic needs and preferences of the children, we did not provide a standard set of toys. Two cameras were used, each directed at one interaction partner: one was placed on a tripod (usually directed at the child) and one was manually handled by the researcher in order to ensure optimal angle views. Because the observations related to this study were part of a broader project, parents and children were already familiarized with the researcher and the presence of camera equipment in the context of other test administrations.

Afterwards, the videotaped observations were scored using an adapted version of the Child Behavior Rating Scale-Revised (CBRS; Mahoney, 1998) and the Maternal Behavior Rating Scale-Revised (MBRS; Mahoney, 2008). Most dyadic interaction scales have been developed in the context of attachment research in typically developing children and are being specifically linked to attachment style as the outcome variable. In contrast, the choice for the MBRS and CBRS was inspired by its previous usage in groups of young children with developmental and intellectual disabilities as well as its aim to evaluate (aspects of parental behavior specifically related to) broader child development (Hostyn, Petry, Lambrechts, \& Maes, 2009; Mahoney \& Nam, 2011). Validation research on the original MBRS and CBRS showed a Cronbach's Alpha of .89 and Kaiser-Meyer-Olkin of .86 (Kim, Sung, \& Hyun, 2000). The CBRS identifies two domains of children's interactive engagement: attention (composed of the items: attention to activity, persistence, involvement and cooperation) and initiation (composed of the items: initiating activities, joint attention and affect). The MBRS identifies four domains of parental interactional style: responsive/child oriented behavior (composed of 
the items: sensitivity to child's interest, responsivity and effectiveness), affect/animation (composed of the items: acceptance, enjoyment, expressiveness, inventiveness and warmth), achievement orientation (composed of the items: achievement and praise) and directive behavior (composed of the items: directiveness and pace). All items were rated on a 5-point Likert scale, indicating a low to high presence of the behavioral dimension. A general description of MBRS and CBRS items is presented in Table 2.

[Insert Table 2 here]

In a first stage of the coding process, the first author, a colleague researcher and two master's students explored the suitability of the CBRS and MBRS within this specific target group, by rating test observations and through conversation focused on resolving disagreements. For three items (effectiveness, directivity and cooperation), modifications to the original scoring instructions were made in order to preserve the core concept and ensure comparability of Likert ratings with previous research using the CBRS and MBRS. Regarding effectiveness, the original instructions stated that the parent's score is also dependent on the ability to gain a reciprocal exchange with the child, characterized by balanced turn taking. Since the cognitive (and communicative) limitations of the children often impede the presence of this interactional feature within this target group, it was not taken into account. Furthermore, parent's initial choice of activity and provision of materials was not regarded as directive behavior, since free play of the children in this target group is often impeded by their (cognitive and) motor limitations. Finally, (absence of) compliance was only rated when the parents' requests/suggestions were in concordance with the cognitive and motor capabilities of the child. 
In a second stage, two other master's students carried out the final ratings. Several measures were taken to ensure the reliability of the rating process. First of all, raters were unfamiliar with the parent-child dyads and other test results. Further, prior to the final rating process, they completed a 30-hour training until they had reached over $90 \%$ mutual agreement within one point and over $50 \%$ exact agreement. In order to reduce observation effects, the first two minutes of the video-taped observations were not taken into account during the scoring process, as this was regarded as an adjustment period. For each dyad, the subsequent 10 minutes were rated. The fragment was then further divided into five time sections of two minutes, since the test-runs showed that considerable fluctuations in child behavior (e.g. varying levels of attention, characteristic of this target group) and subsequent parental behavior impeded the raters' ability to reliably decide on overall scores. The test-runs also showed two minutes to be an adequate time range, since the use of a broader interval reduced rating reliability and the use of a smaller interval did not provide enough information to reliably decide on scores on all behavioral domains. Each time section was examined three times. During a first inspection, parent and child were simultaneously observed and raters took general notes on the participants' behaviors. During the second inspection, the raters focused on parental behavior and decided on a score for all 12 items of the MBRS. After the third inspection, focusing on the child, the seven items of the CBRS were scored. Child communication profiles were used to enhance the raters' understanding of the communicative utterances of the participating children. These profiles, filled in by parents, provided information on the ways a child usually communicates through gaze direction, facial expression, sound, posture and/or movement. Each time after rating a group of five dyads, a reliability check was performed to verify if retraining was necessary. Since overall agreement never dropped below the initial level, retraining did not occur. For each rater, the scoring process resulted in 95 section scores (19 items x 5 time sections) per dyad. 
Overall, the interrater agreement within one scale point was $94 \%$. For $56 \%$ of section scores exact agreement was obtained. Rater differences were dealt with by averaging raters' section scores that differed one scale point (38\% of all scores). Section scores differing more than one scale point ( $6 \%$ of all scores) were discussed and decided upon through a consensus rating procedure. Interrater agreement for the $12 \mathrm{MBRS}$ and $7 \mathrm{CBRS}$ individual scale items ranged from $41 \%$ to $63 \%$ and $47 \%$ to $73 \%$ (exact) and from $86 \%$ to $100 \%$ and $84 \%$ to $97 \%$ (within one scale point), respectively. At last, the five section scores per item were averaged, resulting in 19 item scores for each dyad. For 1 parent-child dyad, only 3 time sections were available and consequently averaged to obtain their item scores (i.e. due to fatigue of the child). Global domain scores relating to the four domains of parent's interactional style and two domains of child's interactive engagement were obtained by averaging item scores.

\subsubsection{Parenting behavior}

Parents were also asked to complete the Parental Behavior Scale for toddlers [PBS; Van Leeuwen, Rousseau, Hoppenbrouwers, Wiersema, \& Desoete, 2011), a self-report measure of observable parenting behavior among parents of children younger than four years, consisting of 46 items rated on a 5-point Likert scale (ranging from occurring 'never' to 'always'). This questionnaire is a modified version of the 'Parental Behavior Scale' aimed at children between 8 and 14 years old, which is characterized by a good reliability and validity (Van Leeuwen \& Vermulst, 2004). The questionnaire comprises six parenting domains: warmth/support $(n=15)$, autonomy support $(n=7)$, supervision and safety $(n=4)$, discipline $(n=10)$, rules and structure $(n=7)$, and rewarding $(n=3)$. Global ratings on these six domains of parenting behavior were obtained by averaging item scores. This instrument was developed in the context of 'JOnG!', a longitudinal study on a myriad of child and family factors in children of different ages (Van 
Leeuwen et al., 2011). Out of approximately 3000 participants of this longitudinal study in Belgium, we selected a control group of typically developing children $(n=25)$ nearest matching our own study group as a whole on gender and age of the children as well as gender and educational level of the parents. An exact match was obtained with regard to child gender and parental educational level. Further, the control group consists of 5 fathers and 20 mothers, indicating an exact match on parent's gender was obtained in all but one case. The mean age of the control parents matches closely with the study group (range $=25-44$ years, $M=32.24$ years), while the mean age of the control children turns out to be slightly lower (range $=12-43$ months, $M=33.76$ months).

\subsection{Data Analysis}

To provide a general characterization of parental behavior and children's interactive engagement, descriptive statistics (mean, standard deviation, median and range of scores) are presented. Since the difference between mean and median scores was generally small $(M=$ 0.09), average scores are used to describe the results in-text. Further, Mann-Whitney U tests were used for the comparison of the study group and the matched control group on the PBS. We opted for a non-parametric test because of the small sample size and the presence of nonnormality in the data. Effect sizes $r$ were calculated by dividing the $Z$-statistic by the square root of $N$ (Fritz, Morris, \& Richler, 2012). For interpretation of effect sizes, we followed the guidelines of Cohen (1988), regarding 0.5 as a large effect. Finally, Spearman rank correlations were used for evaluating the relation between parental behavior (i.e. the four domain scores of the MBRS and six domain scores of the PBS) and child behavior (i.e. the two domain scores of the CBRS). Here also, Cohen's guidelines were followed for evaluating the strength of the correlations. Bootstrap confidence intervals for the statistically significant correlations are presented in-text. Bootstrapping is a technique from which the sampling distribution of a 
statistic is estimated by taking repeated samples (with replacement) from the data set (Field, 2009), resulting in a more robust estimation in case of a small sample size (Adèr \& Adèr, 2008) and the presence of non-normality in the data (Wood, 2004). In advance, scatterplots of the related variables were visually inspected for monotonicity of the relationship. A priori poweranalyses (using G*Power 3.1; Faul, Erdfelder, Lang, \& Buchner, 2007) with a specified power of 0.8 (Moore \& McCabe, 2005) revealed that the current sample size allows for a reliable detection of large, but not small or medium correlations and group differences. Lastly, the possible influence of several child and parental characteristics on the results was evaluated by comparing the obtained values (mean scores) of the complete sample and a partial sample, based on a specified variable.

\section{Results}

\subsection{General Characterization of Parental Behavior (Aim 1)}

\subsubsection{Parents' interactional style}

The mean, standard deviation, median and range of item and domain scores on the Maternal Behavior Rating Scales are presented in Table 3. The average item scores related to the first two domains, responsive/child oriented behavior and affect/animation, were situated within the middle range of the 5-point Likert Scale. The other two domains showed low average item scores, with achievement orientation yielding even lower results than directive behavior.

[Insert Table 3 here]

\subsubsection{Parenting behavior}

The mean, standard deviation, median, range and comparison results of the domain scores on the Parental Behavior Scale for toddlers are presented in Table 4. With regard to our 
study group, scores on all but one parenting domain were situated within the higher range of the 5-point Likert Scale, with rewarding and supervision/safety yielding the highest scores. Only disciplining the child yielded a relatively low score. Relative to the other parenting domains, the scores on autonomy support indicate a high variability of this type of parenting behavior within the participant group.

At a more detailed level, the three items related to rewarding consistently received high ratings (with average item scores ranging from 4.48 to 4.64), indicating that parents often show their appreciation of children's positive behavior through verbal comments, facial expression and/or touch. Similarly, the four items related to supervision/safety were rated consistently high (with average item scores ranging from 4.24 to 4.80), indicating that parents monitor their children and the safety of their environment closely.

Furthermore, high average scores related to parental warmth/support indicate that parents play with their child, provide distraction when the child is restless, imitate the child's vocalizations, sing or hum to the child and show the child how to use a toy (with average scores ranging from 3.76 to 3.92$)$. Even higher scores (4.12-4.72) were evident with regard to holding the child on the lap, making the child laugh (e.g., by tickling), cuddling, talking to the child during nursing, examining why the child cries or behaves differently than usual and comforting the child. Only pointing at and naming things (2.84), looking at books together with the child (2.64) and explaining the child how something works (2.52) yielded lower results.

Four items related to autonomy support yielded relatively high scores (ranging from 3.56 to 4.24), indicating the parents provide their children with the opportunity and encouragement to try new things while simultaneously supporting them when they do not 
succeed. Encouraging children to make their own choices as well as completely taking over when the child does not succeed, yielded relatively lower scores (2.92 and 2.88). The last item, 'I give my child small assignments that he can do on his own', yielded a very low average item score of 1.88 .

The relatively high average scores on three items with regard to rules and structure (4.00-4.24) indicate that parents provide their children with a fixed daily routine. Also, parents avoid overstimulation of the child (3.56), but push through when the child does not want something, such as eating or sleeping (3.40). Relatively lower scores were given to the two items about clearly telling the child what is not allowed (2.52) and quickly allowing what the child wants or demands (2.96).

Similarly, with regard to discipline, allowing what the child wants or demands in order to avoid upsetting the child yielded a rather low average score of 2.68. The same goes for three items on disciplining the child verbally, through facial expression and body posture, with average scores between 2.56 and 2.64. However, disciplining the child by ignoring unwanted behavior, giving a time-out, providing (positive or negative) punishment, giving a light slap or handling the child in a rough manner, yielded even lower scores (1.20-1.96). Standard deviations of all average item scores ranged from 0.44 to 1.53 , indicating variability in parental behavior across parent-child dyads.

In the control group, the same general pattern is recognizable: all domains yielded scores within the higher range of the scale, except for discipline. However, Mann-Whitney U tests showed that the control group's scores were significantly higher for autonomy support $(|r|$ $=0.43)$, rules and structure $(|r|=0.54)$ and particularly discipline $(|r|=0.74)$; all characterized 
by rather large effect sizes. Also, standard deviations indicate a lower variability of scores on all domains compared to the study group.

At item level, there were no striking differences between the two groups concerning rewarding behavior and supervision of the child. With regard to the other four domains, some items showed statistically significant group differences, with p-values ranging from 0.000 to 0.046 and the absolute value of effect sizes ranging from 0.28 to 0.84 . In the context of warm and supportive parenting, the parents in our study group more often cuddle with their child and mimic the sounds they make, but showed lower levels of pointing at and naming things, looking at books together and explaining how something works. The group difference in autonomy support is illustrated by lower scores on encouraging the child to try new things and to make own choices, compared to the control group. Also, parents in our study group less often reported letting the child discover the environment on its own or giving the child small assignments that he can do on his own. Furthermore, with regard to rules and structure, parents in our study group reported less persistence when the child does not want something, less strict bed times and lower levels of telling the child what is not allowed. At last, parents in our study group reported lower scores on almost all discipline items. Only disciplining the child by ignoring unwanted behavior or handling the child in a rough manner and allowing what the child wants or demands in order to avoid upsetting the child yielded comparable results to the control group.

[Insert Table 4 here]

\subsection{General Characterization of Children's Interactive Engagement (Aim 2)}

The mean, standard deviation, median and range of item and domain scores on the Child Behavior Rating Scales are presented in Table 5. Average scores on the two domains, attention 
and initiation were situated within the lower range of the 5-point Likert scale. Average item scores showed some diversity: persistence and initiating activities yielded very low results, while scores on attention to activity and affect were situated within the relatively higher range of the scale. Variability in participant's scores was higher for attention than initiation, with attention to activity yielding the highest variability and initiating activities yielding the lowest variability.

[Insert Table 5 here]

\subsection{Associations between Parental and Child Behavior (Aim 3)}

Spearman correlations between domain scores on the MBRS, PBS and CBRS are presented in Table 6. The majority of domain scores within the different instruments were significantly and positively related. Hereafter, only the correlations with a relatively small bootstrap interval range (i.e. $\leq .50)$ are discussed. Within the MBRS, responsivity and affect/animation were highly correlated (95\% CI $[.59, .90])$. Within the PBS, warmth/support was highly correlated to autonomy support $(95 \%$ CI $[.55, .87])$ as well as rules/structure (95\% CI $[.48, .86])$. Autonomy support and rules/structure were also mutually correlated (95\% CI $[.33, .83])$. Within the CBRS, attention and initiation of the child were highly correlated (95\% CI $[.45, .94])$. For all other significant correlations, the lower limits of the bootstrap intervals ranged from .04 to .26 and the higher limits ranged from .66 to .86 .

MBRS domain scores were not related to PBS domain scores. Only directive behavior within the interaction and reported autonomy support rendered a significant and positive correlation with a $95 \%$ CI between .05 and .76 . 
At last, no significant correlations were found between the PBS and CBRS domain scores. However, responsive behavior (MBRS) was significantly and positively related to attention $(95 \% \mathrm{CI}[.11, .79])$ as well as initiation (95\% CI [.12, .84]).

[Insert Table 6 here]

\subsection{Child and Parental Characteristics}

In order to evaluate the possible influence of several child and parental characteristics on the results, we compared the obtained values (mean scores and correlations) of the complete sample and partial, more homogeneous, samples. The sample was subdivided according to the specified variables (child age, child gender, child sensory impairments, parent's age, parent's gender, parent's educational level, parent's activity status, country of residence and parity) and each time, the largest part was used in the analysis in order to preserve as much sample size as possible. Within the partial samples, mean scores on parental interactional style and children's interactive engagement never differed more than .12 from the values obtained by analysis of the whole sample Mean scores on parenting behavior never differed more than .25 . The largest differences $(\geq .20)$ indicate that parents report less supervision when the child is younger and does not have a sensory impairment, and parents report less disciplining behavior when they are highly educated. The pattern of correlations within the partial samples (i.e. strength as well as direction) was generally comparable to the values obtained by analysis of the whole sample. Also, significance levels were comparable amongst higher (>.60) correlations, while correlations below .60 often did not reach the .05 significance level within the partial samples, as could be expected based on the power analysis. Further details and concrete results are available from the first author upon request. 


\section{Discussion}

\subsection{Conclusions}

\subsubsection{Characterization of parental behavior}

The parents of young children with a significant cognitive and motor developmental delay in this study are generally sensitive and responsive towards their children within an interaction characterized by acceptance, warmth and enjoyment. Although parents 'guide' the interaction by offering toys and/or initiating activities, they do not often attempt to direct their child's immediate behavior. Further, since encouragement of children's sensorimotor and cognitive achievement and the use of verbal praise occurs infrequently, the interaction is more oriented at creating a mutually shared experience rather than being regarded as a teaching opportunity.

In earlier research by Mahoney, Kim and Lin (2007), all four dimensions of parental behavior towards young children with mild to moderate disabilities clustered near the midpoint of the scale, with their highest ratings in directiveness and their lowest in achievement orientation. In our target group, the same midpoint tendency for responsive behavior and affect can be observed. However, levels of directiveness as well as achievement orientation are strikingly lower. These results are surprising, since earlier research indicates that parents are more directive when children have lower developmental levels, presumably in an attempt to optimize children's opportunities for developmental learning (Spiker, Boyce, \& Boyce, 2002). It is possible that parents' interaction patterns are influenced by previous experiences with their child, either by knowing/assuming the child does not understand, respond to or appreciate (verbal, gestural, physical,...) directives or by having few hopes for developmental benefits resulting from a directive/achievement oriented parental approach. The objection could be made that the low ratings of directiveness are due to the modified scoring instructions regarding 
directiveness. However, the modification was made to ensure the representativity of the ratings in relation to the core concept, i.e. to avoid a nonsensical inflation in parental directiveness scores due to the motor limitations of the child.

Based on self-report, the parents of young children with a significant cognitive and motor developmental delay in this study are generally warm and supportive towards their child, monitor the child and his/her environment closely and often show appreciation of the child's positive behavior. They also report high levels of autonomy support and the provision of rules and structure; however significantly less than parents of typically developing children. Disciplining the child is rarely reported and yields the largest difference with the control group of parents with typically developing children.

Parenting items requiring a higher level of cognitive and/or motor functioning of the child (e.g. verbal explanations, supporting independent exploration,...) yield relatively low scores in our study group, indicating that parents adapt their behavior to the child's (dis)abilities. Also, it is highly likely that the (relatively) low levels of discipline and rules/structure are related to low levels of undesirable child behavior. Furthermore, the greater variability in parenting scores within the study group could be related to the greater variability in children's cognitive and motor functioning, compared to the control group.

In conclusion, the same conceptual domains of interactional style and parenting behavior used in research on typically developing children and children with mild disabilities are present, and thus applicable, in research on the specific target group of young children with a significant cognitive and motor developmental delay. However, there appear to be notable differences in frequency levels (e.g. with regard to discipline) as well as in the concrete 
operationalization of some parenting domains (e.g. parental effectiveness within the interaction).

\subsubsection{Characterization of children's interactive engagement.}

Children within the study group are moderately attentive during an interaction with their parent, showing some involvement and cooperation, but are rarely persistent in practicing actions and/or vocalizations. The children seldom initiate new or altered activities, but show some attention to the adult (primarily through establishing eye contact). Children generally display low intensity enjoyment throughout the interaction.

In Kim and Mahoney (2004), the interactive engagement levels of young children functioning cognitively at approximately half their chronological age or lower were compared to typically developing children, matched for chronological age. Results indicated lower scores on all 7 CBRS items in children with disabilities (significantly so for attention to activity, persistence, cooperation and joint attention). The scores in our study group are generally comparable to those of children with disabilities within the study of Kim and Mahoney (2004); except for persistence (more than one scale point lower) and initiation (almost two scale points lower). A possible explanation for these strikingly lower scores is that persistence and initiation are strongly influenced by the additional motor limitations in our study group.

\subsubsection{Associations between parental and child behavior}

The majority of parent's behavioral dimensions showed moderate to high, but not perfect, correlations within the respective instruments. Between instruments, observed parental interactional style and reported parenting behavior were not related in all but one case. This could indicate that the MBRS and the PBS each provide unique information on different types 
of parental behavior. The results do suggest that parents who report higher levels of autonomy support also show more directive behavior within the interaction, but the wide bootstrap confidence interval prevents us from drawing a reliable conclusion on the strength of this relation.

Reported parenting behavior was not related to children's interactive engagement. However, parent's responsivity and child orientedness within the interaction proved to be significantly related to children's attention as well as initiation. Here also, the wide confidence interval prevents us from drawing a reliable conclusion on the strength of this relation. Nevertheless, this result confirms the importance of sensitive responsivity as the primary variable in parenting research (Mahoney \& Nam, 2011), regardless of the child's developmental level, as well as in interactional research on persons with severe and multiple disabilities (Hostyn \& Maes, 2009). However, it is unclear whether parental responsivity elicits child engagement, child engagement elicits parental responsivity, or both processes influence each other bidirectionally.

\subsection{Strengths and Limitations}

Parental behavior is a broad concept, for which a variation of coding and classifying procedures has been used (Mahoney \& Nam, 2011). Conclusions drawn in parenting research are thus directly dependent on the way the variables are operationalized. In this explorative study, we incorporated two types of measures of parental behavior. Through the questionnaire, information is gathered on the frequency of general parenting behavior across many contexts and over time. Using the observational method, parents' behavioral dimensions within the concrete and momentary context of a parent-child interaction are studied. While both data collection methods are possibly influenced by social desirability bias, the latter could also be 
influenced by the rater's subjective interpretation. By providing clear instructions (before selfreport as well as observation), incorporating adjustment time (during data collection as well as coding) and keeping close track of inter-rater reliability, we attempted to constrain possible bias.

This study's results need to be interpreted with caution. For one, the sample size in this study is fairly limited, yet unavoidable due to strict eligibility criteria (e.g. combination of cognitive and motor limitations and small age range in the children), low prevalence rates and other practical and emotional barriers experienced by parents. Therefore, this study is unable to reliably detect small or medium correlations and group differences. Also, the non-randomized sampling method impedes generalizability. For example, even though we targeted children as young as 6 months, the youngest participant in our sample is 14 months. Since we primarily recruited participants indirectly through professionals, our insight into a possible selection bias and the reasons behind non-participation is fairly limited. In addition, children with severe and multiple disabilities often show fluctuations in their behavioral patterns over time (Goldbart, 1994; Munde, Vlaskamp, Ruijssenaars, \& Nakken, 2011). Therefore, the momentary observation of children's interactive engagement might not be fully representative of the child's daily functioning. Furthermore, this study does not give rise to causal statements. We have merely described the co-occurring presence of parental and child behavioral dimensions. However, the correlational nature of the analyses within this study correspond to the presumed bidirectionality of parental and child behavior. We cannot rule out the possibility that different children elicit different parental responses (Collins et al., 2000) and that children with various disabilities, genotypes, and temperament styles react differently to similar parental input (Maccoby, 2001; Mahoney \& Nam, 2011). 
Because of the very scarce knowledge in the current research literature, we think there is great merit in providing a general characterization of parental and child behavior in the specific group of children with significant cognitive and motor limitations as such. Whenever possible, results were also compared to previously collected data (i.e. PBS) and current literature on the variable of interest (i.e. MBRS and CBRS) to gain more specific insight into how these behavioral dimensions are present in other target groups. It would have been interesting to extend the use of a control group to the observational data, in order to perform a more reliable comparison of the study group's results. However, because of the multiplicity and complexity of the participant's limitations, it is unclear which characteristics are most relevant for the selection of a control group. Therefore, the use of multiple control groups (incorporating children with no or other types and levels of disabilities) could have provided a more extensive and insightful comparison. Regrettably, both options would have compromised the feasibility of this specific study.

Finally, a rough comparison of the mean scores and correlations in the complete sample and partial samples showed relatively small differences based on child age, child gender, child sensory impairments, parent's age, parent's gender, parent's educational level, parent's activity status, country of residence and parity. However, due to the limited sample size we are not able to formulate reliable, statistically robust, conclusions regarding this topic.

\subsection{Suggestions for Future Research}

First, we would like to point out that our target group consists of individuals with such profound intellectual disabilities that no existing standardized tests are applicable for a valid estimation of their level of intellectual capacity (Nakken \& Vlaskamp, 2007). Established norms are usually based on scores of typically developing persons and are therefore not reliable 
for groups who achieve extremely low scores (Resing \& Blok, 2002). Also, the assessment procedure is challenging, due to fluctuating attention and achievement levels as well as the additional motor limitations. Additionally, Weis (2014) reports that the measurement of intellectual functioning with standardized, individual intelligence tests is typically done in children of approximately five years or older. Hence, it is not common for the children in our target group to receive a definite diagnosis at this young age. Therefore, we opted to use the description 'significant cognitive (and motor) developmental delay' instead of applying the term 'profound ID'. A strong suggestion for future research is the development and (international) validation of an assessment procedure for determining the level of cognitive functioning in young children with significant cognitive and motor limitations.

Further, we would recommend studying a larger and randomized group of participants in order to increase representativeness and statistical power. However, combining the results of several small-sample replication studies and gathering data longitudinally can be a more feasible way to gather knowledge on this specific target group. In this regard, we have experienced that joining forces through (inter)national collaboration can be an ideal tool, e.g. to increase sample sizes and generalizability as well as to stimulate theoretical and methodological reflection.

In reference to this study's concrete results, further research should go beyond correlational analyses and make an attempt to disentangle the direction(s) in which child and parental behavior influence one another. Longitudinal analyses, taking into account the child's initial functioning, could provide evidence that "parenting conceivably affects -rather than simply accompanies or follows from- child adjustment" (Collins et al., 2000). Further, the questionnaire and rating scale used in this study capture qualitative aspects of parental behavior 
but fail to assess specific behavioral linkages (Bornstein \& Manian, 2013). In-depth analysis of the observational data would allow us to explore the reciprocal sequences of parental and child behavior within this target group, taking into account the considerable fluctuations in child and parental behavior that are characteristic of this target group. Both approaches (longitudinal and sequential) could help pave the way for the development of specific parenting support interventions within the target group of young children with a significant cognitive and motor developmental delay.

As said, this study primarily focuses on qualitative aspects of parental behavior. However, children's experiences also differ in terms of the number of times parents interact with them as well as the types of activities they do together (Mahoney \& Nam, 2011). Incorporating these variables into future studies, combining data on different family members (e.g. parental figures and siblings) whenever possible, would give us a more comprehensive view of the child's primary context and its influence on child behavior and development. 


\section{Acknowledgements}

We would like to thank all participating families for their time, effort and enthusiasm. We are also grateful to Marthe Jacobs and Valesca Deckers for their involvement in the final rating process. This work was supported by the Research Foundation in Flanders, Belgium [grant ZKC9876].

\section{References}

Adèr, H. J., \& Adèr, M. (2008). Advising on research methods: A consultant's companion. Johannes van Kessel Publishing.

Baker, J.K., Fenning, R.M., Crnic, K.A., Baker, B.L., \& Blacher, J. (2007). Prediction of social skills in 6-year-old children with and without developmental delays: contributions of early regulation and maternal scaffolding. American Journal on Mental Retardation, $112,375-391$.

Belsky, J. (1984). The determinants of parenting: A process model. Child development, 83-96.

Bornstein, M. H., \& Manian, N. (2013). Maternal responsiveness and sensitivity reconsidered: Some is more. Development and psychopathology, 25(4pt1), 957-971.

Bronfenbrenner, U. (1986). Ecology of the family as a context for human development: Research perspectives. Developmental psychology, 22(6), 723.

Bronfenbrenner, U. (2001). Bioecological theory of human development. In: Smelser, N. J. \& Baltes, B.P. (Eds.). International encyclopedia of the social and behavioral sciences, Vol. 10. New York: Elsevier.

Chadwick, O., Cuddy, M., Kusel, Y., \& Taylor, E. (2005). Handicaps and the development of skills between childhood and early adolescence in young people with severe intellectual disabilities. Journal of Intellectual Disability Research, 49(12), 877-888.

Cohen, J. (1988). Statistical Power Analysis for the Behavioral Sciences, 2nd Edition. Hillsdale: Lawrence Erlbaum. 
Collins, W. A., Maccoby, E. E., Steinberg, L., Hetherington, E. M., \& Bornstein, M. H. (2000). Contemporary research on parenting: the case for nature and nurture. American Psychologist, 55(2), 218.

Dyches, T.T., Smith, T.B., Korth, B.B., Roper, S.O., \& Mandleco, B. (2012). Positive parenting of children with developmental disabilities: a meta-analysis. Research in Developmental Disabilities, 33, 2213-2220.

Fagnart, D. (2011). Bewegingsbeperkingen. In: Maes, B., Vlaskamp, C., \& Penne, A. (Eds.), Ondersteuning van mensen met ernstige meervoudige beperkingen. Handvatten voor een kwaliteitsvol leven. Acco, Leuven.

Farah, M. J., Betancourt, L., Shera, D. M., Savage, J. H., Giannetta, J. M., Brodsky, N. L., ... \& Hurt, H. (2008). Environmental stimulation, parental nurturance and cognitive development in humans. Developmental science, 11(5), 793-801.

Faul, F., Erdfelder, E., Lang, A. G., \& Buchner, A. (2007). G* Power 3: A flexible statistical power analysis program for the social, behavioral, and biomedical sciences. Behavior research methods, 39(2), 175-191.

Field, A. (2009). Discovering statistics using SPSS. Sage, London.

Ford, D. H., \& Lerner, R. M. (1992). Developmental systems theory: An integrative approach. Sage Publications, Inc.

Fritz, C. O., Morris, P. E., \& Richler, J. J. (2012). Effect size estimates: Current use, calculations, and interpretation. Journal of Experimental Psychology: General, 141(1), 2-18.

Goldbart, J. (1994). Opening the communication curriculum to students with PMLDs. Educating children with profound and multiple learning difficulties, 15-62. 
Gorter, J. W., Ketelaar, M., Rosenbaum, P., Helders, P. J., \& Palisano, R. (2009). Use of the GMFCS in infants with CP: the need for reclassification at age 2 years or older. Developmental Medicine \& Child Neurology, 51(1), 46-52.

Grossman, H. J. (1973). Manual on Terminology and Classification in Mental Retardation. American Association on Mental Deficiency: Special Publication Series, No. 2. Washington D.C.: American Association on Mental Deficiency.

Guralnick, M. J. (2005). Early Intervention for Children with Intellectual Disabilities: Current Knowledge and Future Prospects. Journal of Applied Research in Intellectual Disabilities, 18(4), 313-324.

Guralnick, M. J. (2011). Why early intervention works: A systems perspective. Infants and young children, 24(1), 6 .

Guralnick, M. J., Neville, B., Hammond, M. A., \& Connor, R. T. (2008). Mother's social communicative adjustments to young children with mild developmental delays. American Journal on Mental Retardation, 113, 1-18.

Hastings, R. P., Daley, D., Burns, C., \& Beck, A. (2006). Maternal distress and expressed emotion: cross-sectional and longitudinal relationships with behavior problems of children with intellectual disabilities. American Journal on Mental Retardation, 111, 48-61.

Hogg, J., Foxen, T., \& McBrien, J. (1981). Issues in the training and evaluation of behaviour modification skills for staff working with profoundly retarded multiply handicapped children. Behavioural Psychotherapy (New Series), 9(04), 345-357.

Horn, E., \& Kang, J. (2012). Supporting Young Children With Multiple Disabilities: What Do We Know and What Do We Still Need To Learn?. Topics in early childhood special education, 31(4), 241-248. 
Hostyn, I., \& Maes, B. (2009). Interaction between persons with profound intellectual and multiple disabilities and their partners: A literature review. Journal of Intellectual and Developmental Disability, 34(4), 296-312.

Hostyn, I., Petry, K., Lambrechts, G., \& Maes, B. (2011). Evaluating the quality of the interaction between persons with profound intellectual and multiple disabilities and direct support staff: A preliminary application of three observation scales from parentinfant research. Journal of Applied Research in Intellectual Disabilities, 24(5), 407-420.

Ispa, J. M., Fine, M. A., Halgunseth, L. C., Harper, S., Robinson, J., Boyce, L., ... \& BradySmith, C. (2004). Maternal intrusiveness, maternal warmth, and mother-toddler relationship outcomes: variations across low-income ethnic and acculturation groups. Child development, 75(6), 1613-1631.

Kim, J. M., \& Mahoney, G. (2004). The Effects of Mother's Style of Interaction on Children's Engagement Implications for Using Responsive Interventions with Parents. Topics in Early Childhood Special Education, 24(1), 31-38.

Kim, J. M., Sung, O., \& Hyun, M. (2000). The Validity Study of Parent-child Interaction Rating Scales (MBRS \& CBRS). Korean Journal of Clinical Psychology, 19, 895-904.

Koegel, R. L., Koegel, L. K., \& Carter, C. M. (1999). Pivotal teaching interactions for children with Autism. School Psychology Review, 28(4), 576.

Landry, S. H., Smith, K. E., Swank, P. R., Assel, M. A., \& Vellet, S. (2001). Does early responsive parenting have a special importance for children's development or is consistency across early childhood necessary? Developmental Psychology, 37, 387403.

Larzelere, R. E., Morris, A. S. E., \& Harrist, A. W. (2013). Authoritative parenting: Synthesizing nurturance and discipline for optimal child development. American Psychological Association. 
Larsson, H., Viding, E., Rijsdijk, F. V., \& Plomin, R. (2008). Relationships between parental negativity and childhood antisocial behavior over time: A bidirectional effects model in a longitudinal genetically informative design. Journal of abnormal child psychology, $36(5), 633-645$.

Lerner, R. M., Rothbaum, F., Boulos, S., \& Castellino, D. R. (2002). Developmental systems perspective on parenting. In M. H. Bornstein (Ed.), Handbook of parenting: Vol. 2, Biology and ecology of parenting. 2nd ed. (pp. 315-344). Mahwah, NJ: Lawrence Erlbaum Associates.

Lochman, J. E. (2004). Contextual factors in risk and prevention research. Merrill-Palmer Quarterly, 50(3), 311-325.

Maccoby, E. E. (2001). Parenting and its effects on children: On reading and misreading behavior genetics. The Science of Mental Health: Personality and personality disorder, $51,201$.

Mahoney, G. (1998). Child Behavior Rating Scale (Revised). Cleveland, Ohio: Case Western Reserve University.

Mahoney, G. (2008). Maternal Behavior Rating Scale (Revised). Cleveland, Ohio: Case Western Reserve University.

Mahoney, G., Boyce, G., Fewell, R. R., Spiker, D., \& Wheeden, C. A. (1998). The relationship of parent-child interaction to the effectiveness of early intervention services for at-risk children and children with disabilities. Topics in Early Childhood Special Education, 18(1), 5-17.

Mahoney, G., Kim, J. M., \& Lin, C. (2007). Pivotal behavior model of developmental learning. Infants \& Young Children, 20(4), 311-325.

Mahoney, G., \& Nam, S. (2011). The parenting model of developmental intervention. International review of research on mental retardation, 41, 73-125. 
Moore, D.S. and McCabe, G. (2005). Introduction to the Practice of Statistics, fifth edition. Gordonsville: W. H. Freeman Publishers.

Munde, V., Vlaskamp, C., Ruijssenaars, W., \& Nakken, H. (2011). Determining alertness in individuals with profound intellectual and multiple disabilities: The reliability of an observation list. Education and Training in Autism and Developmental disabilities, 116123.

McCollum, J. A. (2002). Influencing the development of young children with disabilities: Current themes in early intervention. Child and adolescent mental health, 7(1), 4-9.

Nakken, H., \& Vlaskamp, C. (2007). A need for a taxonomy for profound intellectual and multiple disabilities. Journal of Policy and Practice in intellectual Disabilities, 4(2), 8387.

Narvaez, D. (Ed.). (2012). Evolution, early experience and human development: From research to practice and policy. Oxford University Press.

Nelson, C. A. (2000). The neurobiological bases of early intervention. Handbook of early childhood intervention, 2, 204-227.

Palisano, R., Rosenbaum, P., Bartlett, D., \& Livingston, M. (2007). Gross Motor Function Classification System: Expanded and Revised. CanChild Centre for Childhood Disability Research, McMaster University.

Sameroff, A. J. (Ed.) (2009). The Transactional Model of Development: How Children and Contexts Shape Each Other. Washington, DC: American Psychological Association.

Sameroff, A. (2010). A unified theory of development: A dialectic integration of nature and nurture. Child development, 81(1), 6-22.

Spiker, D., Boyce, G. C., \& Boyce, L. K. (2002). Parent-child interactions when young children have disabilities. International review of research in mental retardation, 25(2), 35-70. 
Stadeus, A., Windey, K., Vermeir, G., \& Van Driessche, S. (1994). Tandemlijst voor jonge kinderen met ontwikkelingsmoeilijkheden. Leuven: Garant.

Stams, G. J. J., Juffer, F., \& van IJzendoorn, M. H. (2002). Maternal sensitivity, infant attachment, and temperament in early childhood predict adjustment in middle childhood: the case of adopted children and their biologically unrelated parents. Developmental psychology, 38(5), 806.

Van keer, I. \& Maes, B. (2016). Contextual factors influencing the developmental characteristics of young children with severe to profound intellectual disability: A critical review. Journal of Intellectual and Developmental Disabilities.

Van Leeuwen, K., Rousseau, S., Hoppenbrouwers, K., Wiersema, R. J., \& Desoete, A. (2011). JOnG!: opvoedings- en gezinsvariabelen bij de Vlaamse geboortecohorte 0-jarigen. (SWVG-Rapport 24). Leuven: Steunpunt Welzijn, Volksgezondheid en Gezin.

Van Leeuwen, K., \& Vermulst, A. (2004). Some psychometric properties of the Ghent Parental Behavior Scale. European Journal of Psychological Assessment, 20, 283-298.

Vig, S., \& Sanders, M. (2007). Assessment of Mental Retardation. In Brassard, M. R., \& Boehm, A. E. (Eds.) Preschool assessment: Principles and practices. Guilford Press.

Warren, S. F., \& Brady, N. C. (2007). The role of maternal responsivity in the development of children with intellectual disabilities. Mental Retardation and Developmental Disabilities Research Reviews, 13(4), 330-338.

Wilder, J., Axelsson, C., \& Granlund, M. (2004). Parent - child interaction: a comparison of parents' perceptions in three groups. Disability and rehabilitation, 26(21-22), 13131322.

Wood, E., \& Rosenbaum, P. (2000). The gross motor function classification system for cerebral palsy: a study of reliability and stability over time. Developmental Medicine and Child Neurology, 42, 292-96. 
Wood, M. (2004). Statistical inference using bootstrap confidence intervals. Significance, 1(4), 180-182.

Zhou, Q., Eisenberg, N., Losoya, S. H., Fabes, R. A., Reiser, M., Guthrie, I. K.,... \& Shepard, S. A. (2002). The Relations of Parental Warmth and Positive Expressiveness to Children's Empathy-Related Responding and Social Functioning: A Longitudinal Study. Child development, 73(3), 893-915. 
Table 1

\section{Sample characteristics}

\begin{tabular}{|c|c|c|c|c|c|}
\hline Variable & $n$ & $\%$ & Range & $M$ & $S D$ \\
\hline Children & 25 & & & & \\
\hline \multicolumn{6}{|l|}{ Gender } \\
\hline Male & 7 & 28 & & & \\
\hline Female & 18 & 72 & & & \\
\hline Age (in months) & & & $14-57$ & 38.27 & 10.41 \\
\hline \multicolumn{6}{|l|}{ Sensory impairments } \\
\hline Reduced vision & 10 & 40 & & & \\
\hline Blindness & 2 & 8 & & & \\
\hline Reduced hearing & 1 & 4 & & & \\
\hline Deafness & 2 & 8 & & & \\
\hline \multicolumn{6}{|l|}{ Motor impairments } \\
\hline Hypotonia & 18 & 72 & & & \\
\hline Hypertonia & 10 & 40 & & & \\
\hline Contractures & 2 & 8 & & & \\
\hline Scoliosis & 3 & 12 & & & \\
\hline Others & 5 & 20 & & & \\
\hline \multicolumn{6}{|l|}{ Health problems } \\
\hline $\begin{array}{l}\text { Gastro-intestinal } \\
\text { problems }\end{array}$ & 15 & 60 & & & \\
\hline Heart problems & 0 & 0 & & & \\
\hline Respiratory problems & 8 & 32 & & & \\
\hline Epilepsy & 17 & 68 & & & \\
\hline Others & 8 & 32 & & & \\
\hline Use of feeding tube & 12 & 52 & & & \\
\hline \multicolumn{6}{|l|}{ Etiology } \\
\hline Genetic defect & 13 & 52 & & & \\
\hline Perinatal asphyxia & 2 & 8 & & & \\
\hline Acquired brain injury & 2 & 8 & & & \\
\hline
\end{tabular}




\begin{tabular}{|c|c|c|c|c|c|}
\hline Variable & $n$ & $\%$ & Range & $M$ & $S D$ \\
\hline Unknown & 8 & 32 & & & \\
\hline \multicolumn{6}{|l|}{ Parity } \\
\hline Firstborn & 10 & 40 & & & \\
\hline Not firstborn & 15 & 60 & & & \\
\hline Parents & 25 & & & & \\
\hline \multicolumn{6}{|l|}{ Gender } \\
\hline Male & 6 & 24 & & & \\
\hline Female & 19 & 76 & & & \\
\hline Age (in years) & & & $26-46$ & 33.84 & 4.77 \\
\hline \multicolumn{6}{|l|}{ Highest educational level } \\
\hline Primary education & 2 & 8 & & & \\
\hline Secondary education & 8 & 32 & & & \\
\hline Higher education & 15 & 60 & & & \\
\hline \multicolumn{6}{|l|}{ Activity status } \\
\hline Working full-time & 12 & 48 & & & \\
\hline Working part-time & 7 & 28 & & & \\
\hline $\begin{array}{l}\text { (Consciously) } \\
\text { unemployed }\end{array}$ & 6 & 24 & & & \\
\hline Families & 25 & & & & \\
\hline Number of family members & & & $3-8$ & 4.12 & 1.20 \\
\hline Parent(al figure)s & & & $1-2$ & 1.92 & 0.28 \\
\hline Children & & & $1-6$ & 2.20 & 1.16 \\
\hline One-parent households & 2 & 8 & & & \\
\hline Reconstituted families & 2 & 8 & & & \\
\hline \multicolumn{6}{|l|}{ Country of residence } \\
\hline Belgium & 11 & 44 & & & \\
\hline The Netherlands & 14 & 56 & & & \\
\hline
\end{tabular}


Table 2

Description of MBRS and CBRS items

\begin{tabular}{ll}
\hline MBRS - Responsive/ child oriented behavior \\
\hline Sensitivity to child's interest & The extent to which the parent seems aware of and \\
understands the child's activity or play interests, assessed by \\
parent's engaging in child's activity choice, verbal comments \\
in reference to child's interest and visual monitoring of \\
child's behavior or activity. \\
The frequency, consistency and supportiveness of parent's \\
responses to the child's behaviors. Responses are supportive \\
when they match the child's actions, requests and intentions. \\
The parent's ability to engage the child in the interaction: to \\
gain the child's attention, cooperation and participation. \\
Effectiveness ${ }^{a}$ & $\begin{array}{l}\text { The extent to which the parent's behaviors and } \\
\text { communications accept or affirm the child and what the } \\
\text { child is doing. } \\
\text { Acceptance }\end{array}$ \\
The parent's enjoyment of interacting with the child. There \\
is enjoyment in child's being himself rather than the activity \\
the child is pursuing. \\
The tendency of the parent to communicate and react \\
emotionally toward the child, including the frequency of \\
verbal and nonverbal communications as well as the \\
intensity and animation of these communications. \\
The range of stimulation parents provide; including the \\
ability to find different things to interest the child, different \\
ways of using materials etc. \\
Positive affective expression through pats, lap-holding, \\
caresses, kisses, hugs, tone of voice, and verbal \\
endearments.
\end{tabular}




\begin{tabular}{ll}
\hline Achievement & $\begin{array}{l}\text { Parent's encouragement of sensorimotor and cognitive } \\
\text { achievement, whether through play, instruction, training, or } \\
\text { sensory stimulation. } \\
\text { Quantity of verbal praise given to the child, given for } \\
\text { compliance, achievement or for the child being himself. }\end{array}$ \\
\hline MBRS - Directive behavior & \\
\hline Directiveness ${ }^{a}$ & $\begin{array}{l}\text { Frequency and intensity in which the parent requests, } \\
\text { commands, hints or attempts in other manners (e.g., } \\
\text { physical) to direct the child's immediate behavior. }\end{array}$ \\
Pace & $\begin{array}{l}\text { Parent's rate of behavior, assessed apart from the child's } \\
\text { behavior. }\end{array}$ \\
\hline CBRS - Attention & $\begin{array}{l}\text { The extent to which the child attends to activities, whether } \\
\text { or not the child is actively involved. }\end{array}$ \\
Attention to activity & $\begin{array}{l}\text { The extent to which the child practices actions/vocalizations } \\
\text { and continues to try solutions even though not successfully } \\
\text { reaching his or the adult's goal. } \\
\text { The intensity with which the child is motivated to } \\
\text { engage/participate in the activities regardless of whether } \\
\text { they are adult or child initiated. } \\
\text { The degree to which the child attempts to comply with the } \\
\text { requests or suggestions of the adult. }\end{array}$ \\
Cooperation ${ }^{a}$ & \\
\hline CBffect & $\begin{array}{l}\text { The extent to which the child initiates new or altered } \\
\text { activities, without waiting for the adult's suggestion or } \\
\text { guidance. } \\
\text { The extent to which the child initiates interaction and shares } \\
\text { the attention for an object/event with the adult. } \\
\text { The child's general emotional state during the interaction, } \\
\text { expressed through smiles, laughs or vocalizations. }\end{array}$ \\
\hline Initiating activities &
\end{tabular}

Note. Description of items is based on Mahoney (1998; 2008).

atem was adapted to the specific characteristics of this study's target group. 
Table 3

Overview of item and domain scores on the Maternal Behavior Rating Scale

\begin{tabular}{clll}
\hline MBRS & Mean $($ SD) & Median & Range \\
\hline Responsive/ child oriented behavior & $\mathbf{3 . 0 8}(\mathbf{0 . 5 4})$ & $\mathbf{3 . 1 0}$ & $\mathbf{2 . 2 3 - 4 . 0 7}$ \\
Sensitivity to child's interest & $3.26(0.47)$ & 3.20 & $2.50-4.10$ \\
Responsivity & $3.15(0.55)$ & 3.10 & $2.10-4.00$ \\
Effectiveness & $2.82(0.70)$ & 2.70 & $1.60-4.10$ \\
Affect/animation & $\mathbf{3 . 0 9}(\mathbf{0 . 5 1})$ & $\mathbf{3 . 1 6}$ & $\mathbf{2 . 1 6 - 4 . 2 0}$ \\
Acceptance & $3.23(0.50)$ & 3.20 & $2.50-4.20$ \\
Enjoyment & $3.36(0.54)$ & 3.40 & $2.33-4.20$ \\
Expressiveness & $3.11(0.68)$ & 3.20 & $1.70-4.20$ \\
Inventiveness & $2.59(0.52)$ & 2.70 & $1.60-3.70$ \\
Warmth & $3.16(0.65)$ & 3.10 & $1.90-4.90$ \\
Achievement orientation & $\mathbf{1 . 8 2}(\mathbf{0 . 5 4})$ & $\mathbf{1 . 7 0}$ & $\mathbf{1 . 0 0 - 3 . 3 0}$ \\
Achievement & $1.95(0.67)$ & 1.80 & $1.00-3.50$ \\
Praise & $1.68(0.59)$ & 1.60 & $1.00-3.10$ \\
Directive behavior & $\mathbf{2 . 5 4}(\mathbf{0 . 4 5})$ & $\mathbf{2 . 5 5}$ & $\mathbf{1 . 3 5 - 3 . 3 3}$ \\
Directiveness & $2.37(0.63)$ & 2.20 & $1.20-3.67$ \\
Pace & $2.71(0.38)$ & 2.80 & $1.50-3.30$ \\
\hline
\end{tabular}


Table 4

Overview of domain scores on the Parental Behavior Scale

\begin{tabular}{|c|c|c|c|c|c|c|c|c|}
\hline \multirow{2}{*}{ PBS } & \multicolumn{3}{|c|}{ Study group } & \multicolumn{3}{|c|}{ Control group } & \multicolumn{2}{|c|}{ Comparison } \\
\hline & Mean $(S D)$ & Median & Range & Mean $(S D)$ & Median & Range & $U$ & $Z$ \\
\hline Warmth/support & $3.94(0.43)$ & 3.93 & $3.13-4.53$ & $4.14(0.35)$ & 4.00 & $3.40-4.73$ & 230.50 & -1.594 \\
\hline Autonomy support & $3.31(0.74)$ & 3.29 & $1.86-4.43$ & $3.97(0.36)$ & 3.86 & $3.43-4.71$ & 156.50 & $-3.041 * *$ \\
\hline Supervision and safety & $4.61(0.62)$ & 4.75 & $2.25-5.00$ & $4.57(0.47)$ & 4.75 & $3.50-5.00$ & 269.50 & -0.866 \\
\hline Discipline & $1.90(0.59)$ & 1.80 & $1.00-3.20$ & $2.88(0.32)$ & 2.90 & $2.30-3.40$ & 45.00 & $-5.202 * *$ \\
\hline Rules and structure & $3.54(0.46)$ & 3.57 & $2.14-4.57$ & $4.01(0.32)$ & 4.00 & $3.57-4.71$ & 117.50 & $-3.814 * *$ \\
\hline Rewarding & $4.57(0.58)$ & 5.00 & $3.00-5.00$ & $4.69(0.42)$ & 5.00 & $4.00-5.00$ & 281.50 & -0.665 \\
\hline
\end{tabular}

$* p<.05, * * p<.01$ 
Table 5

\begin{tabular}{llll}
\multicolumn{4}{l}{ Overview of item and domain scores on the Child Behavior Rating Scale } \\
\hline CBRS & Mean $($ SD) & Median & Range \\
\hline Attention & $\mathbf{2 . 6 1}(\mathbf{0 . 5 2})$ & $\mathbf{2 . 5 5}$ & $\mathbf{1 . 6 0 - 3 . 5 7}$ \\
Attention to activity & $3.12(0.76)$ & 3.20 & $1.40-4.50$ \\
Persistence & $1.44(0.63)$ & 1.20 & $1.00-3.00$ \\
Involvement & $2.92(0.70)$ & 2.80 & $1.60-4.20$ \\
Cooperation & $2.95(0.65)$ & 2.90 & $1.67-4.60$ \\
Initiation & $\mathbf{2 . 2 2}(\mathbf{0 . 3 7})$ & $\mathbf{2 . 2 0}$ & $\mathbf{1 . 6 0 - 3 . 3 3}$ \\
Initiating activities & $1.29(0.35)$ & 1.10 & $1.00-2.10$ \\
Joint attention & $2.06(0.61)$ & 2.10 & $1.00-3.80$ \\
Affect & $3.31(0.53)$ & 3.30 & $1.80-4.20$ \\
\hline
\end{tabular}


Table 6

Overview of Spearman correlations between domain scores of the MBRS, PBS and CBRS

\begin{tabular}{|c|c|c|c|c|c|c|c|c|c|c|c|c|}
\hline Domain scores & M1 & M2 & M3 & M4 & $\mathrm{P} 1$ & $\mathrm{P} 2$ & P3 & $\mathrm{P} 4$ & P5 & P6 & $\mathrm{C} 1$ & $\mathrm{C} 2$ \\
\hline \multicolumn{13}{|l|}{ MBRS } \\
\hline M1. Responsive behavior & - & & & & & & & & & & & \\
\hline M2. Affect/animation & $.80 * *$ & - & & & & & & & & & & \\
\hline M3. Achievement orientation & $.49^{*}$ & $.47 *$ & - & & & & & & & & & \\
\hline M4. Directive behavior & .27 & .36 & $.49 *$ & - & & & & & & & & \\
\hline \multicolumn{13}{|l|}{ PBS } \\
\hline P1. Warmth/support & -.05 & .02 & -.09 & .39 & - & & & & & & & \\
\hline P2. Autonomy support & -.08 & .01 & .09 & $.45^{*}$ & $.76 * *$ & - & & & & & & \\
\hline P3. Supervision/safety & -.17 & -.09 & -.03 & .09 & .38 & $.46^{*}$ & - & & & & & \\
\hline P4. Discipline & -.20 & -.04 & .18 & .25 & .36 & .40 & .28 & - & & & & \\
\hline P5. Rules/structure & -.29 & -.17 & -.04 & .12 & $.73 * *$ & $.63 * *$ & $.41 *$ & $.50 *$ & - & & & \\
\hline P6. Rewarding & -.15 & -.19 & -.13 & .01 & $.59 * *$ & $.59 * *$ & $.48^{*}$ & .24 & $.50^{*}$ & - & & \\
\hline \multicolumn{13}{|l|}{ CBRS } \\
\hline C1. Attention & $.51^{*}$ & .20 & .06 & -.05 & .05 & .08 & -.01 & .11 & .15 & .06 & - & \\
\hline C2. Initiation & $.56 * *$ & .39 & .16 & .00 & -.15 & .00 & -.15 & .14 & -.09 & -.16 & $.78 * *$ & 一 \\
\hline
\end{tabular}

$* p<.05, * * p<.01$ 